\title{
Vertigem passada a limpo: uma lista do espólio de W. G. Sebald
}

Douglas Valeriano Pompeu

Universidade Livre de Berlim

\section{Resumo}

O breve artigo a seguir busca apresentar uma lista de anotações de W. G. Sebald presente em seu espólio literário, com o intuito de abrir caminho para uma abordagem de um conjunto de manuscritos ainda pouco explorados pela fortuna crítica do autor: as listas. Focado em uma possível poética de anotações e citações e na materialidade da oficina literária do escritor, interessa-me aqui apresentar o manuscrito menos por um interesse crítico genético que possa provocar, do que por sua qualidade enquanto gênero, constituído por uma economia e programa textuais próprios.

Palavras-chave: w. g. sebald, literatura alemã, hibridismo

\begin{abstract}
This brief article seeks to present a list of W.G. Sebald's notes found in his literary estate with the goal of facilitating the consideration of a set of manuscripts that have received little attention in his critical reception so far, i.e., lists. Focusing on the possibility of a poetic of note-making and quotations and in the material nature of the writer's literary craft, my interest here is to present the manuscript less as an attempt at provocative genetic criticism than in its quality as a genre endowed with its own textual program and economy.
\end{abstract}

Key-words: w. g. sebald, german literature, hybridism

Entre as constatações que talvez podemos tirar da avolumada fortuna crítica de uma obra tão sugestiva como a de W. G. Sebald a que mais me parece vir à tona é o aproveitamento insistente e repetitivo de temas e abordagens que representam mais as formas do discurso em voga da crítica de uma época do que de um cinismo resistente na obra do autor. Por outro lado, ao ler seus livros, e neste ponto entendemos o filão deixado pelo autor aos críticos, sabemos que eles são capazes de conduzir o leitor a um conjunto de vertigens retroalimentares, como, por exemplo, a da representação e a da referência literária, para citar apenas as duas mais evidentes, e que, justamente por isso, o risco corrente por boa parte de sua crítica é o de se espiralizar nas sugestões da obra e cair na armadilha do mise en abyme sem notá-lo, quando, em grande parte, é dessa queda (humanista, para alguns, filológica, para outros) que ela, a sua obra, se ocupa.

Em outro momento, cheguei a apontar esta sugestão como uma performance constitutiva das narrativas sebaldianas. Sebald tem a mania de provocar um leitor compulsivo por meio de um dos seus recursos mais recorrentes, isto é, deixando rastros, 
marcas, costuras, iscas, que, desobediente ou não, este leitor seguirá obstinado sem notar que ao produzir um texto sobre a obra, não se aproximou mais de seu entendimento, mas que se tornou produto centrifugado da própria obra, ou seja, que em poucos casos chegará a se recuperar da vertigem. Nesta ocasião, interessava apresentar aos leitores brasileiros o espólio de Sebald, adquirido e preservado pelo Arquivo Literário Alemão (DLA), em Marbach, Alemanha, no qual o material disponível ao investigador é um reflexo ordenado de um processo interminável de escrita e leitura. E não me referia naquele momento a uma imagem refletida de um espelho comum, mas na estrutura do espelho usado em periscópios, ferramenta que o próprio autor aproxima de sua narrativa.

Diante deste amontado de materiais autorreferenciais que me causavam ansiedade e me faziam perder-me em labirintos de leitura, o que me chamava a atenção em meu primeiro contato com o espólio, e o que assumi para fins de organização de minha pesquisa, foi que os personagens criados por este autor funcionavam como pontos de concentração, ou melhor, como pontos de vertigem tanto na estrutura da obra como na do espólio. Para cada nome, lugar e datas presentes na obra há documentos, imagens, catálogos, recortes de jornal, cartas, agendas e cópias de todo tipo, inclusive, uma quantidade imensa de cópias (de cópias) de textos, testemunhando a existência e dando pistas dos caminhos textuais de um autor que, diante desse material, cada vez mais se aproxima da imagem de um leitor compulsivo. Uma compulsão não só presente em seu espólio e em seus personagens, mas no modo em como o autor levou a etimologia de "persona" até as suas últimas consequências, dando voz ao outro através de um processo intrincado de apropriações.

Mas se, por um lado, minha escolha parecia dar uma resposta às minhas perguntas de pesquisa, por outro, ela não sabia lidar satisfatoriamente com um tipo de documento muito presente tanto na obra como no espólio de Sebald: suas listas. Desde então, um número razoável de textos críticos já se ocupou notavelmente da aproximação do trabalho de Sebald com o método do colecionador e do bricoleur, e principalmente com a sua compulsão por arquivos, mas em uma revisão de sua fortuna crítica, pouca repercussão se encontra sobre o seu interesse e sua obsessão por listas ${ }^{1}$. Em 2012, Tom McInnes Lee publicava talvez o primeiro esforço focado nesta questão. Em seu artigo

\footnotetext{
${ }^{1}$ Tampouco em Saturn's Moon - W. G. Sebald Handbook, Catling (2011), esse tema ou o documento que procuro apresentar aqui é motivo de atenção.
} 
The Lists of W. G. Sebald, o autor analisa brevemente a presença de listas em Die Ringe des Saturn (1995). Assumindo o conceito de listas não-sintáticas do antropólogo Jack Goody, Lee lança luz sobre listas de tipos de escrita ou inscrição que compõem largamente a narrativa de Sebald: fotografias, tabelas, assinaturas, diagramas, mapas, carimbos, cadastros, rascunhos e anotações. Lee acentua, sem qualquer problematização, que para Goody este tipo de lista não-sintática é constitutiva de culturas pré- ou não-literárias, e arrisca afirmar que listas não são apenas uma forma de escrita não-sintática em constante tensão com a escrita sintática de Sebald, como também estão presentes no seu próprio estilo literário:

The list is perhaps Sebald's most widely used and variable form of non-syntactical writing, a key part of his formal and stylistic peculiarity. His lengthy sentences frequently spill over into catalogues and inventories, and the entire structure of his narratives is list-like. Discrete episodes accumulate alongside each other, rather than following a narrative arc where episodes of suspenseful gravity overshadow the significance of minor events. (LEE, 2012)

Em 2013, em uma breve estadia no DLA devido a um outro projeto, encontreime por acaso com a pesquisadora argentina Maria Virginia Castro, autora dos primeiros textos no Cono Sur a discutir a influência de Borges na obra de Sebald². Virginia, ocupava-se naquele momento com a biblioteca física e virtual do autor e as influências de autores pós-borgianos nas narrativas sebaldianas. Em conversa e por meio de Virginia, descobri a existência de uma lista de anotações do autor sobre a qual ela estava pensando em escrever um artigo. Por fim, sentamo-nos horas durante a estadia em Marbach decifrando o manuscrito de Sebald para passar a limpo a lista em questão. A surpresa tinha duas faces: não ter tropeçado nesta lista anteriormente no espólio e muito menos no material crítico que havia consultado e dar-se conta de que estávamos diante de uma lista autoreferencial de citações de poéticas. Neste contexto, além de reconhecer na lista a estrutura não-sintática mencionada por Lee, tomei consciência de Vertigine della Lista (2009), de Umberto Eco, autor que marca presença clara e sugestiva no ensaio de Sebald sobre o pintor Jan Peter Tripp, em Logis in einem Landhaus:

\footnotetext{
${ }^{2}$ MARIA VIRGINIA CASTRO: Borges, un precursor velado en la obra de W. G. Sebald" (2009) y "Jorge Luis Borges y los post borgianos Ítalo Calvino, Claudio Magris y Danilo Kiš en la biblioteca de escritor de W. G. Sebald" (2014), W.G. Sebald, Leser von Jorge Luis Borges. Bemerkungen über die Bedeutung von Borges in Sebalds Prosa in Ibero-Amerikanisches Jahrbuch für Germanistik, 2011.
} 
O tempo perdido, a dor das lembranças e a imagem da morte estão aqui reunidas em um cofre de memórias como citações da própria vida. No fundo, o ato de recordar não é outra coisa do que uma citação. E a citação usada em um texto (ou em uma imagem) nos obriga, como escreve Eco, a uma revisão de nosso conhecimento de outros textos e imagens e de nosso conhecimento do mundo. Isso, por sua vez, exige tempo. Ao passo que o despendemos, entramos no tempo narrado e no tempo da cultura. ${ }^{3}$

A citação de Eco aqui não provém de Vertigine della Lista, senão de Opera Aperta (1962), no entanto, pode ser lida como um fio condutor que se estende até Vertigine. No ensaio sobre Tripp, ela vem a reboque de uma reflexão sobre o tema da morte e do tempo perdido (proustiano) em suas imagens e justamente logo depois de uma longa descrição do quadro de um interior em La Cadiere d'Azur, no sul da França. Recortada do ensaio e descolada da imagem de Tripp, a citação é uma referência clara, mais uma vez, à própria poética vertiginosa sebaldiana. Muito mais tarde e posterior à obra de Sebald, em Vertigine della Lista, Eco continua a assumir a citação, ou melhor, o tecido de citações como uma via de entendimento da infinidade do mundo. Não é por acaso que, devido a um convite do museu de Louvre para organizar um evento temático, Eco decide dar forma a um tema que atravessa sua obra desde de Opera Aperta em um livro de citações, no qual a voz do autor emerge mais pelas mãos da curadoria e do que da escrita.

Talvez por buscar exemplos extremos, Sebald não está entre os autores citados. Quando se ocupa com as listas de vertigem, seu precursor é A Biblioteca de Babel de Borges e seus objetos são os Fictional Worlds (1986), de Thomas Pavel, Baku (1927), de Heinrich Johan Vogeler, Street Scene in New York (1920), de Joaquín Torres García, A Biblioteca (1949), de Maria Helena Vieira da Silva, Problema arithmeticum de rerum combinationibus (1622), de Pierre Guldin, Harmonie Universelle (1636), de Marin Mersenne, Cinquenta pinturas abstratas que vistas da distância de duas jardas se convertem em três Lenins disfarçados de chineses e vistas a uma distância de seis jardas aparecem como a cabeça de um tigre (1963), de Salvador Dalí, sem título

\footnotetext{
${ }^{3}$ Die eingebüßte Zeit, der Schmerz der Erinnerungen und die Figur des Todes sind hier in einem Andenkenschrein versammelt als Zitate aus dem eigenen Leben. Das Andenken ist ja im Grunde nichts anderes als ein Zitat. Und das in einen Text (oder in ein Bild) einmontierte Zitat zwingt uns, wie Eco schreibt, zur Durchsicht unserer Kenntnisse anderer Texte und Bilder und unserer Kenntnisse der Welt. Das wiederum erfordert Zeit. Indem wir sie aufwenden, treten wir ein in die erzählte Zeit und in die Zeit der Kultur. (Sebald (2009), p. 184)
} 
(1987), de Alighiero Boetti, Horizon de la doctrine humaine (1693), de Leibniz e Cem Mil Bilhões de Poemas (1961), de Raymond Queneau. De Pavel a Queneau a conclusão de Eco é que o que chamamos de saber, ou seja, nossa tentativa de mensurar ou entender o mundo, se dá através da produção de listas infinitas que chegam a extremos vertiginosos como no caso dos anjos desastrados de Pavel, compiladores de compêndios, enciclopédias e miscelâneas de referências a sentenças verdadeiras.

Feita de referências literárias a Umberto Eco, Italo Calvino, Borges, Virginia Woolf, Nabocov, Giorgio Bassani, Umberto Gambetta e Montaigne a lista preservada no espólio, mesmo não correspondendo a uma lista extrema como as apresentadas por Eco, pode ser aqui considerada como uma lista de vertigem no âmbito da obra compulsiva do Duque da Vertigem, como Javier Marías intitulou Sebald uma vez. Nomeada pelos seus arquivistas como citações de poética e anotações (poetologische Zitate und Notizen), sem data e escrita sobre folhas pautadas, a lista composta pelo que consideramos ser 20 notas escritas em alemão, inglês e italiano reflete em sua forma a própria atividade da anotação de Sebald, seu programa e sua estrutura, e leva o leitor a valorar o gênero textual da anotação literária, capaz de revelar em si uma operação própria de uma micro-técnica da notatio mencionada por Roland Barthes em suas aulas para A Preparação do Romance (2005): seu modo dominante de produção não é a formulação, mas o próprio gesto de anotar. A mão invisível do autor e as páginas que prepara exibem a disponibilidade e a dispensabilidade que conduz à reflexão da prática da escrita. Ora sua grafia se compacta e se firma em versos como um haiku em uma das pontas da folha, ora se dilata e se alonga até os limites da página.

Diante das 20 páginas anotadas por Sebald, e principalmente diante do uso que faz do seu espaço em branco, seu preenchimento e sua interrupção (uma vez interrompido somente quase no limite inferior da página pela anotação "Montaigne -> Italy", outra vez pela expressão "Poética do Excurso"circulada e ligada por uma seta a uma referência ao nome de Gambetta) é possível tirar de sua materialidade uma espécie de programa de anotação constituído por uma contingência oportuna, e contrária ao propósito. Mathias Thiele, em seu ensaio Notizen. Zur Poetik und Genealogie der kleinen Prosaform 'Aufzeichnung' (2014) ${ }^{4}$, arrisca-se a estruturar uma poética da anotação em cinco pontos programáticos que partem das aulas de Barthes, da Opera Aperta de Eco, das anotações de Peter Handke, Elias Canetti e, entre outros, das

\footnotetext{
4 "Notas. Sobre a poética e genealogia da pequena prosa das 'anotações"” (tradução minha)
} 
anotações dos diários do cantor suíço Mani Matter, retirados de seu espólio e publicados em Sudelhefte/Rumpelbuch (2011), do qual, para exemplificar um caso de disponibilidade, de associação livre e intuição presentes na poética da anotação, separa e reproduz uma anotação curiosa do letrista, que, por minha vez, reproduzo aqui para aproximar-me da lista em discussão:

Para poder escrever é preciso atingir um estágio, como o que se encontra algumas vezes tarde da noite: onde pensamentos passam a palavras sem esforço, como se não houvesse qualquer dificuldade na formulação, onde as palavras saem da pena como correm os bombeiros alarmados: comprometidos com o alvo, sem pensar nos passos necessários para o alcance, institivamente e sem temer a queda nas escadas. Na medida que parte-se desta sensação para outra, na qual cada palavra torna-se problemática, onde se hesita subitamente entre as mil possibilidades de construção de uma frase e se progride como se entalhassse a imagem de seus pensamentos em granito, cada golpe muito bem pensado e aplicado com esforço físico, quando se cai dentro deste processo, pode-se, no mesmo instante, interrompe-lo, pois então já se bloqueou a intuição e logo se torna impossível recupera-la. Nosso intelecto é diante ela uma forcinha modesta, com a qual não compensa trabalhar. - Por outro lado, vale lembrar a afirmação de Oscar Wilde sobre o trabalho do poeta: 'O que você fez hoje pela manhã? - Pus uma vírgula! - E pela tarde? -Tirei-a novamente.'O que também é verdade. ${ }^{5}$

Justamente este descer alarmante de escadas nas anotações de Matter parece-me constituir o movimento da lista de citações de Sebald. Da primeira vez que as li, pensava em buscar um propósito em cada uma de suas sentenças, como havia feito em minha primeira investigação sobre o espólio, isto é, encontrar a realização literária final desta anotação, em grau zero, dentro da obra publicada pelo autor. A tarefa não é absurda e muito menos sem valor. No entanto, ela corre o risco de ignorar mais uma vez um procedimento material e formal elementar que se repete em toda a poética

\footnotetext{
${ }^{5}$ Um schreiben zu können, muß man ein Stadium erreichen, wie es sich manchmal, in späten Abendstunden beim Sprechen einstellt: wo sich die Autsch e Öhlschläger (2014)Gedanken mühelos in Worte verwandeln, als ob es keine Formulierungsschwierigkeiten gäbe, wo die Worte aus der Feder laufen wie Feuerwehrleute bei einem Alarm: dem Ziel verpflichtet, ohne an die Schritte zu seiner Erreichung zu denken, instinktiv und ohne zu fürchten, daß sie die Treppe hinunterfallen könnten. Sobald man aus dieser Gefühlslage in jene andere kommt, wo jedes Wort problematisch wird, wo einem plötzlich die tausend Möglichkeiten des Satzbaus in den Sinn kommen und man sich vorkommt, als müsse man das Bild seiner Gedanken in Granit meißeln, jeden Schlag vorher wohl überlegend und mit Kraftaufwand ausführend, wenn man da hineinrutscht, kann man ebensogut aufhören, denn man hat die Intuition dann verscheucht und wird sie so bald nicht wieder herausholen können. Unser Intellekt ist gegen sie ein bescheidenes Kräftlein, mit dem zu arbeiten sich nicht lohnt. - Andererseits ist zu erinnern an den Ausspruch Wildes über die Arbeit des Dichters: ,Was hast du heute getan? - Ein Komma eingesetzt! Und am Nachmittag? - Hab' ich's wieder weggenommen.' Was auch wahr ist. (Matter, 2001, apud Thiele, 2011, p. 167)
} 
vertiginosa de Sebald e que procurei focar ao abrir este artigo. No atual contexto, portanto, sua leitura talvez interesse mais quando a consideramos como uma atividade sem propósito. Instalá-la no horizonte de uma obra, como busquei fazer com listas e rascunhos para o projeto Austerlitz, fez-me naquele momento perder de vista a autorreferencialidade, expressa em suas próprias configurações. Dito de outra forma, se a lista incita o crítico por parecer exibir provas para o crime das influências do autor, ela também pode ser lida menos por meio do estatuto de key-words, de esboço ou de projeto e mais por meio de sua dinâmica contingencial, na qual uma citação puxa a outra por associação e alarme.

Vale ainda lembrar que, no caso de Sebald, apesar de a pena do autor perambular livre na anotação, toda sua obra é um inventário de citações, no qual o autor indica seus caminhos e nomeia seus pares de anotação:

A mão do escritor ${ }^{\text {que tem de estar presente }}$ assinala

um rastro, que está ali para aquele que

o reconhece e busca lê-lo ${ }^{6}$

Como se vê na lista abaixo, seu movimento de escrita, ou os caminhos da mão, traçam um exercício de apropriações, de cópias e transcrições de textos alheios na forma de um diálogo incansável e monótono, como o próprio autor assume, com os mortos. Valendo-se das metáforas de Boris Groys (2002), essa seria a mão escrevente que escava a tumba do autor, exumando seus pares na espiral de um mise au tombeau:

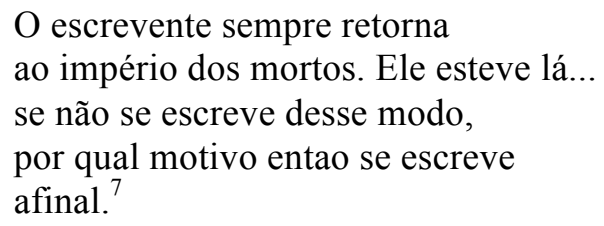

Por isso, antes de motivar uma investigação sobre influências, estas notas (como em parte sua obra e seu espólio) revelam um exercício aparentemente trivial de anotação daquilo que foi lido ou escrito em outra parte, como se agora, diante da página

\footnotetext{
${ }^{6}$ die Hand des Schreibers der präsent sein muß ${ }^{\text {zeichnet }}$ eine Spur, die für den da ist, der sie erkennt und zu lesen versucht (Sebald, Poetologische, A:Sebald, DLA, Marbach)

${ }^{7}$ Der Schreiber geht immer wieder ins Totenreich zurück. Er ist drüben ge $=$ wesen... wenn man nicht so schreibt, zu welchem Zweck schreibt man dann überhaupt. (idem)
} 
montada com a palavra do outro, o autor (re)citasse ao espelho para assumir sua própria voz. Uma voz-fantasma provocada pelo ato material de trans- e reescrever copiosamente alhures aquilo que se deseja levar sempre consigo, antes que isto tudo se "afogue em caos". Não à toa é com "Abscheiberei” que o autor abre sua primeira página. Um neologismo esdrúxulo, entre tantos outros da lista, que expressa, no entanto, esse material suspeito ${ }^{8}$ resultante da bricolagem 9 : abschreiben - descolar o texto de uma página, colando-o em outra, "colar", como sugere a metáfora em português brasileiro para roubar, apropriar dos resultados encontrados por outro; reescrever, transcrever, de um lado a outro, um texto; "Abschreiberei", substantivo para a ação repetiviva, recorrente de abschreiben, sinônimo de plagiarismo, mas neste caso sem o plágio:

Citação como homenagem (contra plágio $\&$ paródia $)^{10}$

Supostamente partindo da máxima de Barthes, segundo a qual escrever é citar sem aspas, o passo seguinte de Sebald parece ser o de se separar, em um primeiro momento - no momento breve e ligeiro da anotação - dos escritores, e colocar-se antes na posição de um funcionário da escrita, de um zeloso Bartleby. Seu gesto se aproxima assim do ofício exigido diaramente do escrevente ou do escrivão:

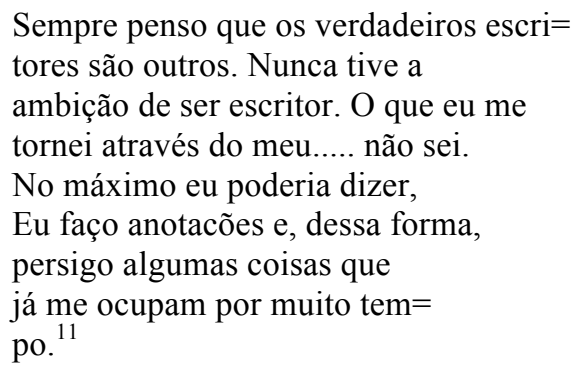

\footnotetext{
${ }^{8}$ Refiro-me aqui aquele limite ou cortejo da arte com o ridículo do seu próprio naufrágio que constitui e emerge, com mais frequência que imagina a fortuna crítica do autor, em sua obra. Na maior parte do tempo, os personagens de Sebald oscilam entre o colecionador, o arquivista e o bricoleuer outsider compulsivo por Nippes e arte Kitsch Cf. Nippes. Beheimatung in kleiner Form, IMORDE, Joseph (2014) e Kitsch and W. G. Sebald, THIRLWELL, Adam (2013).

${ }^{9}$ Cf. Uma oficina poética de lembranças. POMPEU, Douglas (2014) In Aletria, n. 24, v. 2 "Literatura e Fotografia"

${ }^{10}$ Zitat als Hommage (gegen Plagiat

\& Parodie). (idem)

${ }^{11}$ Ich denke immer, daß die richtigen Schrift=

steller andere sind. Ich hatte nie die

Ambition ein Schriftsteller zu sein. Was ich

durch meine.... geworden bin, weiß

ich nicht. Allenfalls könnte ich sagen, ich mache Aufzeichnungen und gehe auf

diese Weise gewissen Dinge nach, die mich schon die längste Zeit beschäfti= gen. (idem)
} 
Tal fragmento ratifica sua escrita descuidada, com frouxidões sintáticas, ou mesmo não-sintáticas, e o uso abusivo de orações relativas ao montar sua lista. Em particular, o uso das relativas pelo escrevente - marca de trivialidade e desapego produz nas anotações, assim como no caso do conjuntivo da prosa sebaldiana, um efeito ambíguo de difícil tradução para o português, e sua repetição causa certa náusea no leitor, que precisa negociar a cada nova frase um sentido que pretende seguir. Náusea, aliás, anunciada já de partida:

determinação de sentido/polissemia/abertura

algo vibra no leitor, sobrevem uma

oscilação $^{12}$

Essa determinação de sentido exigida pelo leitor torna-se ainda mais complexa e intrincada diante de uma poética da anotação sem propósito envolvida em uma economia de anotação que irrita os limites do próprio sub- ou micro-gênero. Citar e anotar muitas vezes se fundem, deslocando e desdobrando os limites do ato de anotar em um processo comum no universo de Sebald, ou seja, a intersecção entre a intuição poética e o documento. Neste caso, talvez seja justamente a denominação de seus pares o que mais despista o leitor. Qual o sentido de trazer na anotação sua autoria quando o que se pretende é tornar porosas as fronteiras entre a anotação literária e a citação, senão a vertigem ${ }^{13}$

Há ainda um último fator relacionado a sua materialidade que fortalece a leitura deste manuscrito como uma prática livre de um projeto específico, talvez até livre da determinação de um gênero: a pressa da caligrafia, contrastada com a perícia da cesura de suas sentenças, assim como o material usado na escrita -lápis, caneta, pincel marcador - expressam sua quase instantaneidade e concomitância, que em conjunto, revela fases de produção separadas entre si. Alguém poderia dizer, por exemplo, que estes manuscritos não passam de fichamentos. É conhecido, no entanto, que Sebald praticava anotações tanto nos exemplares de sua biblioteca pessoal e impessoal, quanto

\footnotetext{
12 Sinnbeschluß/ Polysemie/ Offenheit im Leser vibriert etwas, kommt ein Schwingung (idem)

${ }^{13}$ Essa questão é central para Gabriel Blackwell, em Madeleine E. (2016), narrativa inteiramente composta de anotações do leitor-autor, mas que, diferentemente dos livros de Sebald, apresenta-se na forma de um conjunto de anotações e citações em uma espécie de pré-romance, de preparação ou de uma lista de anotações para um projeto impossível.
} 
as praticava em fichas pautadas e organizadas alfabeticamente. $\mathrm{O}$ esquema narrativo de Austerlitz, por exemplo, encontra-se esboçado na contra-capa de um exemplar de Jardin de Plantes. Qual a dificuldade em aceitar estas páginas como um exercício diário e constante de apropriação intelectual e material da escrita alheia sem considerá-las como práticas tangenciais próprias da falência da imaginação? Apontando para esta consideração a respeito da prática de anotações, Antonio Marcos Pereira, em ensaio sobre a poética da anotação do escritor uruguaio Mario Levrero, confere a este gênero um lugar ativo para o entendimento de um autor e sua obra:

um escritor abdica de imaginar coisas e começa a anotar coisas, substituindo em sua literatura a invenção de outros sujeitos, espaços, situações por uma espécie de contínuo investimento no registro do que lhe ocorre. Mas talvez o que a torne mais interessante seja o fato de que a anotação não é apenas "registro", e seu lugar não é o da zona de passividade que habitualmente relegamos ao escrito, como resultado de uma operação do intelecto e da sensibilidade. O que mais me captura nessas narrativas de Levrero é o agenciamento conferido à escrita: o empenho na escrita como propiciadora de transformação, de mudança de quem escreve. (PEREIRA, 2016, p.2)

De todo o comentário, a transformação mencionada por Pereira sobre as anotações de Levrero clareia um caminho possível para a leitura da lista vertiginosa de Sebald. Desviar a anotação de um horizonte proposital que chamamos de obra e passar a considerá-la como prática na transformação do autor, devolve sentido a um manuscrito, cuja dificuldade de interpretação, talvez se encontre na resistência em aceitar que Sebald está insistentemente passando apropriações a limpo. Talvez, considerar o valor ativo e transformador desta prática, não nos proteja, como leitores, de cair nos abismos provocados pela obra e pela lista, mas pode nos oferecer, pelo menos, a paisagem da queda. 
Anotações e citações de poética ${ }^{14}$

(Poetologische Zitate und Notizen)

\footnotetext{
${ }^{14}$ A lista foi transcrita, enumerada e diagramada por mim e por Maria Virginia Castro e segue respectivamente as páginas do manuscrito. Em alguns momentos tivemos dúvidas com respeito à caligrafia do autor e adotamos a notação entre colchetes para designar que a passagem é considerada ilegível.
} 
o trabalho com os textos

passar a limpo

copiação, inserções

concatenações.

Tolstói deve ter escrito

G \& P 7 x - de pé

a medida certa da responsa-

bilidade frente aos leitores

2

ambiguidade - eco - ressonância

reverberação

determinação de sentido/polissemia/abertura algo vibra no leitor, vem uma oscilação

que não pára de se espantar com quão bem a coisa está feita.

Parece que o tempo está, antes de tudo representado na prosa narrativa.

A mão do escritor ${ }^{\text {que tem de estar presente }}$ assinala um rastro, que está ali para aquele, que o reconhece e busca lê-lo

Eco: de fato é a sequência das circunstâncias, que constitui no romance a fábula, não necessariamente linear. sequência log. ABC'; narrada BAC'

Eco: Há histórias compostas de quase nada, nas quais o tempo do narrado cria-se em poucas frases, enquanto o tempo da narração é extremamente longo (Gogol: o casaco) contra Verne/Dumas

Eco: tempo da citação: quando um texto cita um texto anterior, ele leva o leitor a uma revisão de seus- outros textos \& seu conhecimento do mundo sua competência enciclopédica.

"Para entender a obra, é preciso sair da obra \& explorar o que die Arbeit an den Texten

Ins Reine schreiben

Abschreiberei, Einfügungen

Verknünpfungen.

Tolstoi soll K. \& F. 7 x geschrieben haben _im Stehen

das richtige Maß der Verantwortlichkeit vor den Lesern

2

\section{Ambiguität -Echo-Resonanz Reverberation}

Sinnbeschluß/ Polysemie/ Offenheit im Leser vibriert etwas, kommt ein Schwingung

3

daß man nicht aufhört, sich zu wundern wie gut die Sache gemacht ist.

Es scheint, daß die Zeit vor allem in der erzählenden Prosa dargelegt ist

die Hand des Schreibers ${ }^{\text {der präsent sein muß }}{ }^{\text {zeichnet }}$ eine Spur, die für den da ist, der sie erkennt und zu lesen versucht

Eco: tatsächlich ist die Abfolge der Zustände, die im Roman die Fabel konstituiert, nicht notwendig linear. log. Abfolge ABC'; Erzähl. BAC'

Eco: Es gibt Geschichten, die aus fast nicht bestehen, in denen die Zeit des Erzählten sich in wenigen Sätzen erschopft, während die Zeit der Erzählung überaus lang ist (Gogol: Der Mantel) against Verne/ Dumas

Eco: Zeit des Zitats: Wenn ein Text einen Früheren Text zitiert, bringt er den Leser zu einer Durchsicht seiner-anderer Texte \& seiner Kenntnis der Welt seiner enzyclop. Kompetenz.

„um das Werk zu verstehen, muss man aus dem Werk herausstreben \& erkunden, was 
o tempo narrado, o tempo do narrar,

o tempo psicológio do leitor,

o tempo histórico, o tempo da

cultura:

as muitas gradações do passa-

-do: não é uma construção com

três andares, imp. Perf \& PP.

senão mais uma paisagem

com muitos terrenos

transitivos entre si.

Isto tem que simular a estru-

tura do tempo de uma frase:

assim quando alguém volta

por acaso do pass. para o pres-

ente para simular um pass.

mais profundo.

Citação como homenagem (contra plágio \& paródia)

Postmod. Aulas que realçam algo mais radical, que não se permite mais inserir-se na trad. do Modernismo.

Diferenciação organizada, policentrismo, irregularidade - estética neobarroca imagem do tempo a música - variações

Colecionadores trazem objetos perdidos consigo -fotografias, p.ex. - pois eles não podem suportar (não podem suportar o pensamento) que tudo continuamente afoga-se em caos. Ilha de esperança ordem melhor acabada em si mesma.

Saram. seus esforços como ${ }^{\text {um geógrafo voluntário }}$ seriam de breve utilidade, falando objetivamente, sem a inclusão da prova documental, ou de uma cópia fiel da existência, não apenas real como oficial de uma não existência dos sujeitos destas biografias.

Busca por uma pessoa (Saramago

\section{Senhor José}

Todos os Nomes)

Em albuns fotográficos

[iligível]

ele olha a

imagem: sente

seus olhos cheios

de lágrimas, omitido

sente-se o modo atroz como o tempo pa-

ssa. Ele passa \& não se percebe

nem uma vez. Era manhã

há apenas um instante atrás \& agora está die erzählte Zeit, die Zeit des Erzählens, die psychologische Zeit des Lesers, die historische Zeit, die Zeit der Kultur:

Die vielen Abstufungen der Vergangenheit: nicht ein Gebäude mit dreistockwerken, Imp. Perf \& PP. sondern eher eine Landschaft mit vielen miteinander über $==$ gehendenTerrainen.

Das muß man in der Zeitstruktur eines Satzes simulieren:

So wenn man etwa aus der

Verg. zurückgeht in die Gegen= Wart, um eine tiefere Verg. vorzutäuschen.

\section{Zitat als Hommage (gegen Plagiat \& Parodie)}

Postmod. ${ }^{\text {Lesungen, die auf }}$ etwas Radikaleres abheben, das sich nicht mehr im trad Modernismus einordnen läßt.

organisierte Differenzierung, Polyzentrismus, Irregularität_neobarrocken Ästhetik Zeitbild die Musik-Variationen

Sammler tragen verlorene Dinge zusammen -Fotographien z.B. -weil sie es nicht er= tragen können (den Gedanken nicht er= tragen können) dass fortwährend alles ins Chaos versinkt. Insel einer besseren In sich vollendeten Hoffnung Ordnung.

$\begin{aligned} & \text { Saram. his efforts as a voluntary Geographer would be of little use, objectively } \\ & \text { speaking, without the inclusion of docu= } \\ & \text { mentary proof, or a faithful copy of the } \\ & \text { existence, not only real but official ef } \\ & \text { no existence of the subjects of those } \\ & \text { biographies. } \\ & \text { Suche nach einer Person (Saramago } \\ & \text { Senhor José } \\ & \text { All the names) } \\ & \text { In Album fotographs } \\ & \text { XXXX Bild an: felt } \\ & \text { his eyes fill with } \\ & \text { tears, übergangen }\end{aligned}$
man spürt wie grausam die Zeit ver=
geht. Sie vergeht \& man merkt
es nicht einmal. It was morning
only a moment ago \& now it is




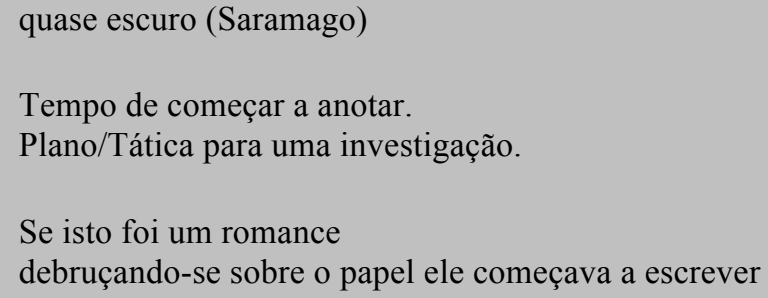

Poética de Excursos

\section{[Excursos Gambetta \\ Gambetta \\ Ciclopicidade}

\section{Calvino}

Escrever é uma ocupação solitária e monótona. \& quando se repete, se é tomado por um interminável desconsolo

de um modo ou de outro o escritor é determinado através do universo pessoal que lhe é concedido.

que a morte tem de ter sem falta um determinado gosto

e o que se leu - algumas páginas de tudo o que foi escrito leu-se apenas algumas páginas

que é preciso poupar muito com o tempo de leitura que se tem.

\section{Literatura consiste em que não}

se escreve exatamente o que se propõe, senão em que se submete a modos misteriosos que vão além do objetivo original.

creio que uma obra estética corresponde à minhas emoções infelizes. Pois a felicidade é seu próprio propósito, certo?

nearly dark (Saramago)

Time to begin making notes.

Plan/ Taktik für eine Untersuchung.

If this was a novel

bending over the paper he began to write

Poetik der Exkurse

\section{Calvino}

Schreiben ist eine eintönige und einsame Beschäftigung. \& wenn man sich wieder= holt, wird man von einer unendlichen Trostlosigkeit erfaßt

8

auf die eine oder andere ist der Schriftsteller bestimmt durch das persönliche Universum, das ihm gegeben ist.

daß der Tod einen ganz bestimmten Geschmack haben muß

und was hat man gelesen -ein paar Seiten, von allem Geschriebenen hat man nur ein paar Seiten gelesen

Daß man sehr haushalten muß mit der Lesezeit, die man hat.

Literatur besteht ja darin, daß man nicht genau schreibt, was man sich vornimmt, sondern an geheimnisvolle Weise darüber hineingeht, über des ursprüngliche Ziel hinaus.

ich glaube, daß ein ästhetischer Werk meiner Emotionen entspricht, die un glücklich sind. Denn das Glück ist ja sein eigener Zweck, nicht wahr? 


\section{Assim a felicidade não exige \\ a transformação em beleza, senão \\ a infelicidade.}

Assim creio eu que todo pensar é uma conjectura.

que nós, toda vez que nos

lembramos do passado, o modificamos, já

que nossa memória é falha.
Also bedarf das Glück nicht der Um wandlung in Schönheit, sondern das Unglück

So glaube ich, daß alles Denken eine Mutmaßung ist.

daß wir jedesmal, wenn wir uns an die

Vergangenheit erinnern, sie modifizieren, zu mal unser Gedächtnis fehlbar ist.
Seguir no trabalho do escritor aquele circuitos elétricos mentais, nos quais pontos espaciais e temporiais distantes entre si são criados \& conectados.

a densidade particular que também pode ser alcançada em uma obra grandiosamente disposta, \& mas que tem sua medida na página única.

as epifanias do tempo perdido

emergindo... [concentradademente] de uma vi= da em um único ponto: o piscar de olhos.

São processos que excedem nossas intencões e possibilidades de controle \&, sendo assim, revestem o caráter de algo transcendente para o indivíduo.

que a observação modifica de certa maneira o observado

Flaubert leu 1500 livros para Bouvard \& Pécuchet. Jean Paul

Inflexões, fantasia \& disciplina de Jean Paul Fantasia não surge do fato de manter uma vida interessante. in der schriftstellerischen Arbeit jenen mentalen [Stromkreisen] folgen, in denen räumlich und zeit= lich weit voneinander entfernte Punkte erfasst $\&$ verbunden werden.

die besondere Dichte, die auch in einem groß an= gelegten Werk erreicht werden kann, \& die ihr $\mathrm{Ma} ß$ doch stets in der einzelnen Seite hat.

die Epiphanien des aus der verlorenen Zeit

auftauchenden... [konzentratisch] eines Le $=$ bens in einem einzigen Punkt: der Augenblick. Das sind Prozesse, die unsere Absichten \& Kontrollmöglichkeiten übersteigen \& somit für das Individuum den Charakter an= nehmen von etwas Transzendentem.

dass die Beobachtung das Beobachtete in gewisser Weise verändert

\section{Flaubert für Bouvard \& Pécuchet 1500 Bücher gelesen. Jean Paul}

Jean Paul's Inflexionen Phantasie \& Sitzfleisch $^{15}$ Phantasie kommt nicht daher, dass man ein interessantes Leben führt.

A descoberta da morte - la ricerca della morte

Per trovare in fondo adena nivece il sero

Contrario // os campos de mortos etruscos em

\section{Cerveteri/Nekropole}

Matilde tema isolamento

aproximar intuição poética e documento de tal modo que um tome a cor do outro
Die Erkundung des Todes -la ricerca della morte Per trovare in fondo adena nivece il sero Contrario // das etruskische Gräberfeld bei Cerveteri/ Nekropole Matilde Thema Abgeschiedenheit poetische Intuition und Dokument einandern so an= zunähern, dass das eine die Farbe des anderen annnimmt

\footnotetext{
${ }^{15}$ Em alemão, "Sitzfleisch", literalmente "assento de carne", refere-se a um sedentarismo disciplinado em realizar atividades sentado, como escrever e ler, por horas a fio.
} 
os dias de neblina de Emilia - a deserta

belezza di Ferrara

escrevo uma literatura com indicações de tempo

e de lugar - fiel à verdade

O escrevente sempre retorna

ao império dos mortos. Ele esteve lá...

se não se escreve assim,

por qual motivo entao se escreve

afinal.

Não escarafunchar a linguagem,

Algo só por temporariamente [???]

também Nabokov (Sebastian p. 387

Me esconder atrás de artifícios

em parte irônicos em parte patéticos

de sintaxe \& retórica.

a lentidão do contar

precisão do detalhe

os suspiros insólitos da coruja

Bassani

11

e o que é a história senão

a imagem que fazemos da his=

tória. Essa imagem aproxima-se

da mitologia, da lenda.

Não me agrada o que escrevo

mais do que eu poderia escrever

ter que viver em atividade imaginária

duradoura

nós não queríamos ser contemporâneos

quem não se considera um gênio, tem que trabalhar com cuidado naquilo que escreve. Esse cuidado

(demasiado) não tem a ver com vaidade; ele é ao contrá= rio uma forma de hu= mildade.

Flaubert que teve essa quase foné_ tica imaginação de estilo; ele quis que cada uma das suas frases pudesse ser lida de forma leve e agradável. die Nebeltage der Emilia - die deserta belleza di Ferrara

schreibe ich eine Literatur mit Zeit \& Orts= angaben - wahrheitsgetreu

Der Schreiber geht immer wieder ins Totenreich zurück. Er ist drüben ge= wesen... wenn man nicht so schreibt, zu welchem Zweck schreibt man dann überhaupt.

Nicht in der Sprache herumfuhrwerken, etwas um bloß zeitweilig [gelichenes?]. Auch Nabokov (Sebastian S. 387

mich selbst hinter teils pathetischen teils ironischen Künsten von Satzbau \& Rhetorik verborgen halten.

die Langsamkeit des Erzählens Genauigkeit der Einzelheit die seltsamen Seufzer des Uhus 11

und was ist die Geschichte anderes als das Bild, das wir uns von der Geschichte ma= chen. Dieses Bild nähert sich der $\mathrm{My}=$ thologie, der Legende.

Mir gefällt nicht, was ich schreibe eher das, was ich schreiben könnte

in dauernder imaginativer Aktivität leben zu müssen

wir wollten nicht Zeitgenössisch sein

wer sich nicht für eine Genie hält, muß sorgfalt verwenden auf das was er schreibt. Diese Sorgfalt (übermäßige) hat nicht mit Eitelkeit zu tun; sie ist im Ge genteil eine Form der Be scheidenheit.

Flaubert, der diese nahezu phone tische Vorstellung von Stil hatte; er wollte, daß jeder seiner Sätze leicht $\&$ angenehmen zu lesen sei. 
A ilusão de uma imitação bíblica como já vi uma vez na casa de um senhor na Alemanha

uma linguagem que é contemplativa.

Borges

12

Notas/

Poética

Perseu consegue dominar a terrível face da

Medusa escondendo-a, assim como conseguiu derrotá-la observando-a pelo espelho. É sempre de uma recusa do olhar direto que Perseu tira a sua força, entretanto, não é uma recusa da realidade do mundo dos monstros, no qual foi "condenado" a viver, que ele carrega consigo, que ele aceita como seu fardo. (Calvino)

que ela, por entidades mais miúdas \& mais finas, vai sendo unida: assim também a narr= ativa, a prosa: A pulverização da reali= dade: Lucrécio

que a frustração da poesia tem algo a ver com o segredo da leveza

Os impulsos e as mensagens imateriais que recebemos: espíritos: o problema de se furtar da gravidade.

que Leopoardi liberta a linguagem de todo seu peso, para que,finalmente, ela se iguale à luz da lua.

\section{Ele escreve como um fantasma}

A procura à leveza como reação ao peso da vida.

privação sofrida e levitação almejada

$\underline{\text { O ideal da leveza }}$

Calvino

Lit(eratura) há de se servir de prosa de todos os recursos. Ela não é, como muitas vezes se pensa, uma forma comparativamente fácil. Muito pelo contrário - sua medida é, como nas formas mais breves, a frase, a linha. Ela é
Das Scheinbild einer Bibl. Attrappe wie ich sie einmal bei einem Herrn in Deutschland gesehen habe

eine Sprache, die nachdenklich ist.

Borges

12

Notes/

Poetik

Perseus kann das Schreckliche Antlitz der Medusa be= herrschen, indem er es verborgen hält, so wie er es zuvor besiegen konnte, indem er es im Spiegel betrachtete. Immer, ist es eine Ablehnung des direkten Anblicks, aus der Perseus seine Kraft bezieht, nicht aber eine Ablehnung der Reali= tät der Monsterwelt, in der zu leben ihm beschieden, die er mit sich herumträgt, die er als seine Bürde annimmt. (Calvino)

$\mathrm{Da}$ die durch feinste $\&$ kleinste Entitäten zusam= Mengehalten wird: so auch die Erzäh= lung, die Prosa: Die Zerstäubung der Reali= tät: Lukrez

daß der Frust der Poesie etwas zu tun hat mit dem Geheimnis der Leichtigkeit

die immateriellen Botschaften \& Impulse, die wir empfangen: Spiriti: das Problem, sich der Schwerkraft zu entziehen.

daß Leopoardi der Sprache von aller Schwere befreit hat, so daß sie schließlich dem Mondlicht ähnlich geworden ist.

Er schreibt wie ein Gespenst

die Suche nach der Leichtigkeit als Reaktion auf die Schwere des Lebens.

erlittene Privation \& ersehnte Levitation

Das Ideal der Leichtigkeit

Calvino

Lit muß sich Prosa aller Resourcen bedienen. Sie ist nicht wie oft ge= dacht wird, ein vergleichsweise ein= fache Form. Ganz im Gegenteil -ihr $\mathrm{Maß}$ ist, wie bei dem knappsten Formen, der Satz, die Zeile. Sie 
unida, eomo o poema, pelas entidades mínimas, por correspondências que quase não se percebe, por um discreto manter e infringir da regra, ecos, cadências, mensagens imateriais, fantasmas vagando entra as linhas.

Calvino \& Lampedusa: sua prosa iria igualando-se aos poucos à luz da lua.

Profundeza histórica/ memória $=$ imprescindível

ideias, clareza de pensamentos: o nar rador não deve ter cabeça vazia, deve ter uma alta

Ele deve ter uma grande medida de empatia em relação com aquilo que ele descreve. Ao mesmo tempo, precisa de uma lasca de minério no coração.

e uma frase certeira, seria aquela que faria uma pedra ter compaixão.

Sempre penso que os verdadeiros escri $=$ tores são outros. Nunca tive a ambição de ser escritor. O que eu me tornei através do meu..... não sei.

No máximo eu poderia dizer, Eu faço anotacões e, dessa forma, persigo algumas coisas que já me ocupam por muito tem= po. E o que me agrada nisso é que posso apresentar a pessoas coisas da minha cabeça.

Prosa narrativa.

Que ela se eleva aparentemente com leveza sobre a vida densa. Como ela se constroi é antes um enigma.

Ela surge talvez de uma certa privação ou carência. Fan= tasia não surge daí porque levamos uma vida interessante.

Forma de trabalho opressora: escrever é uma ocupação monótona e solitária, durante a qual, muitas vezes, somos pegos por um desconsolo profundo. Tem-se muito trabalho com isso, wird, wie das Gedicht, von klein= sten Entitäten zusammengehalten von Korrespondenzen, die kaum jemandem Auffallen, von diskreten Einhalten \& Durchbrechen der Regel, Echos, Kadenzen, immateriellen Botschaften, Geistern die zwischen den Zeilen umgehen.

Calvino \& Lampedusa: seine Prosa Sei allmählich dem Mondlicht ähnlich geworden.

\section{historische Tiefe/ Gedächtnis= unabdingbar}

Ideen/ Gedankenschärfe: der Er zähler darf nicht einen leeren Kopf haben, Er muß ein hohes

Er muß ein hohes Maß von Empathie haben mit dem war er beschreibt. zugleich braucht er im Herzen einen Splitter aus Erz.

und ein richtiger Satz, das wäre einer der einen Stein erbarmen konnte.

\section{4}

Ich denke immer, daß die richtigen Schrift= steller andere sind. Ich hatte nie die Ambition ein Schriftsteller zu sein. Was ich durch meine.... geworden bin, weiß ich nicht. Allenfalls könnte ich sagen, ich mache Aufzeichnungen und gehe auf diese Weise gewissen Dinge nach, die mich schon die längste Zeit beschäfti= gen. Dabei genießt es mich, daß ich den Leuten Sachen vorlegen aus mei= nem Kopf.

\section{Prosa Erzählung.}

daß sie sich scheinbar mit Leichtigkeit über das schwere Leben erhebt. Wie sie sich konstruiert ist eher ein Rätsel.

Sie entstammt vielleicht einer ge= wissen Privation oder Entbeherung. Phan= tasie kommt nicht daher, daß man ein interessantes Leben führt.

Zwangshafte Arbeitsweise: Schreiben ist eine eintönige und einsame Beschäfti= gung, bei der einen oft eine tiefe Trostlosigkeit erfasst. Man hat viel Mühe damit, ist nicht zufrieden - 
e não se satisfaz - um testar e testar eterno

consertar e reescrever.

15

earlier $=$ forms $=$ of German $=$ lang. memory

16

\section{Italo Calvino}

Aqui em Torino consigo escrever pois

o passado e o futuro são mais claros

que o presente

Histórias além de estranhamentos

\& depravações que infligem

as pessoas de hoje.

No século XVIII e XIX tenho

muitos professores e amigos que

nunca me canso de visitar

Para iniciar o processo de escrita, tenho que me esforçar muito, porque sei o que me espera: o esforço e a insatisfação ao tentar e tentar de novo $\&$ corrigir e reescrever.

[Muitas vezes por uma elabo= ração] transgressora conduz ao resultado de êxito e aparentemente espontâneo.

Montale: a linguagem da ver-

dadeira literatura é uma linguagem historicizada.

Os colegas romancistas com seu uso de uma linguagem muito previsível que a prosa requer o encaixe de todas as ressonâncias verbais.

Montaigne -> Italy

18

the phantom (ideas/ thought) in through the mind \& out of the window before you can lag self on its tail.

beauty is only two fingers' breath from goodness

what a muddled \& illogical machine the brain of a writer is ein ewiges Probieren und wieder probieren Ausbessern \& neuschreiben.

earlier $=$ forms $=$ of German $=$ lang. memory

\section{Italo Calvino}

Hier in Turin kann ich schreiben, weil die Vergangeheit und Zukunft deutlicher sind als die Gegenwart

Geschichten jenseits der Entfremdungen \& Depravationen die den heutigen Menschen auferlegt sind.

Im 18. und 19. Jahrhundert habe ich eine Menge Lehrer und Freunde, die zu besuchen ich nie müde werde

um mit dem Schreiben anzufangen, muss ich mir jedesmal eine Willensanstreng= ung abwiegen, weil ich weiß was mich erwartet: die Mühe und die Unzufrie= denheit bei Probieren und Wiederprobieren $\&$ korriegeren und neuschreiben.

[Oft führt um] die geschuldigte Ausar= beitung zur glücklichen und scheinbar spontanen Leistung.

Montale: die Sprache der wahren $\mathrm{Li}=$ teratur ist eine historisierte Sprache.

Die romanschreibenden Kollegen mit Ihrem Gebrauch einer um allzu voraussehbaren Sprache dass Prosa den Einsatz aller verbalen Resonanzen verlangt

Montaigne -> Italy

18

the phantom (ideas/ thought) in through the mind \& out of the window before you can lag self on its tail.

beauty is only two fingers' breath from goodness

what a muddled \& illogical machine the brain of a writer is 
Flaubert spends a month seeking a phrase to des $=$ cribe a cabbage. Tolstoi writes war \& peace seven times over

Considering how much we talk about writers, how much they talk about themselves, it is odd how little we know about them

that a writer is a heavenly apparition that slides across the sky, graves the earth \& vanishes

to write poetry [Keats] against the coming of death $\&$ the indifference of the world

She was careful that his occupation (writing) would not be suspected by the servents or visitors or any person beyond her own family party

For the most part part, of course, novels do come to grief somewhere. The imagination falters under the enormous strain. The insight is confused; it can not longer distinguish between the true $\&$ the false, it has

Flaubert spends a month seeking a phrase to des= cribe a cabbage. Tolstoi writes war $\&$ peace seven times over

Considering how much we talk about writers, how much they talk about themselves, it is odd how little we know about them

that a writer is a heavenly apparition that slides across the sky, graves the earth \& vanishes

to write poetry [Keats] against the coming of death \& the indifference of the world

She was careful that his occupation (writing) would not be suspected by the servents or visitors or any person beyond her own family party

For the most part part, of course, novels do come to grief somewhere. The imagination falters under the enormous strain. The insight is confused; it can not longer distinguish between the true $\&$ the false, it has

Woolf

19

no longer the strength to go on with the vast labour that calls at every moment for the use of so many different faculties

Woolf

Woolf
20

uma certa curiosidade mórbida deflagrada por uma coisa que nunca seria percebida por uma pessoa normal, equilibrada

Ainda se sentir inquieto nessa idade pesquisando por pessoas desaparecidas

\section{[Encontro com leitores} correspondência]

we who write and manipulate the papers, should write the dead and the living in one single archive (Saram., registro que faz esse discurso ilegível) where they will all be in= separable.
20

eine gewisse morbide Neugier ausgelöst von einer Sache, die einem normalen, ausgeglichenen Menschen nie auffallen würde

In diesem Alter noch umgetrieben zu werden in Nachforschungen nach verschollenen Personen.

\section{[Begegnung mit Lesern Korrespondenz]}

we who write and manipulate the papers, should write the dead and the living in one single archive (Saram., Register diese unlesbare Rede hält) where they will all be in= separable. 


\section{Referências}

AUTSCH, Sabiene; ÖHLSCHLÄGER, Claudia (Ed.). Kulturen des Kleinen:

Mikroformate in Literatur, Kunst und Medien. Paderborn: Fink, 2014. 354 S. ISBN

3770556771.

CATLING, Jo (Ed.). Saturn's moons: W. G. Sebald - a handbook. Oxford: Legenda, 2011. XV, 677 S. ISBN 978-1-906540-02-9.

ECO, Umberto. Vertigine della lista: [la presente edizione esce in occasione della Manifestazione Vertiges de la Liste organizzata dal Musée du Louvre nel mese di novembre 2009]. Milano: Bompiani, 2009. 408 S. ISBN 978-88-452-6345-3.

GROJS, Boris; KNOEFEL, Thomas. Politik der Unsterblichkeit: Vier Gespräche mit Thomas Knoefel. München [u.a.]: Hanser, 2002. 207 S. ISBN 3-446-20139-4.

LEE, Tom McInnes. The Lists of W. G. Sebald. M/C Journal, v. 15, n. 5, 2012.

PEREIRA, Antonio Marcos. A poética da anotação em Mario Levrero, 2016. Manuscrito não publicado.

PERRONE-MOISÉS, Leyla. A preparação do romance: Da vida à obra. São Paulo: Martins Fontes, 2005. v. 1. ISBN 8533621361.

SEBALD, W. G. Logis in einem Landhaus: Über Gottfried Keller, Johann Peter Hebel, Robert Walser und andere. 5. ed. Frankfurt am Main: Fischer-Taschenbuch-Verl., 2009. 187 p. (Fischer, 14862). ISBN 978-3-596-14862-2.

SEBALD, W. G. Poetologische Zitate und Notizen. A: Sebald, HS.2004.0001.00044, DLA, Marbach am Neckar. Consulta em 25/9/2014. 